\title{
Correction to: Development and validation of an objective assessment scale for chest tube insertion under 'direct' and 'indirect' rating
}

Julian Ober ${ }^{1}$, Patrick Haubruck', Felix Nickel2, Tilman Walker ${ }^{1}$, Mirco Friedrich², Beat-Peter Müller-Stich², Gerhard Schmidmaier ${ }^{1}$ and Michael C. Tanner ${ }^{1 *}$

Correction to: BMC Med Educ (2018) 18:320 https://doi.org/10.1186/s12909-018-1430-9

Following publication of the original article [1], the author reported that the given name and family name of all authors were swapped. The details are as follows:

Incorrect names in the original article:

Ober Julian

Haubruck Patrick

Nickel Felix

Walker Tilman

Friedrich Mirco

Müller-Stich Beat-Peter

Schmidmaier Gerhard

Michael C. Tanner

Correct names:

Julian Ober

Patrick Haubruck

Felix Nickel

Tilman Walker

Mirco Friedrich

Beat-Peter Müller-Stich

Gerhard Schmidmaier

Michael C. Tanner

The original article has been corrected.
Heidelberg, Germany. ${ }^{2}$ Department of General, Visceral and Transplantation Surgery Heidelberg University Hospital, D-69120 Heidelberg, Germany.

Published online: 20 February 2019

Reference

1. Julian $\mathrm{O}$, et al. Development and validation of an objective assessment scale for chest tube insertion under 'direct' and 'indirect' rating. BMC Med Educ. 2018;18:320. https://doi.org/10.1186/s12909-018-1430-9.

\section{Author details}

'HTRG - Heidelberg Trauma Research Group, Center for Orthopedics, Trauma Surgery and Spinal Cord Injury, Trauma and Reconstructive Surgery,

Heidelberg University Hospital, Schlierbacher Landstrasse 200a, D-69118

\footnotetext{
* Correspondence: michael.tanner@med.uni-heidelberg.de

${ }^{1}$ HTRG - Heidelberg Trauma Research Group, Center for Orthopedics, Trauma

Surgery and Spinal Cord Injury, Trauma and Reconstructive Surgery,

Heidelberg University Hospital, Schlierbacher Landstrasse 200a, D-69118

Heidelberg, Germany

Full list of author information is available at the end of the article
}

(c) The Author(s). 2019 Open Access This article is distributed under the terms of the Creative Commons Attribution 4.0 International License (http://creativecommons.org/licenses/by/4.0/), which permits unrestricted use, distribution, and reproduction in any medium, provided you give appropriate credit to the original author(s) and the source, provide a link to the Creative Commons license, and indicate if changes were made. The Creative Commons Public Domain Dedication waiver (http://creativecommons.org/publicdomain/zero/1.0/) applies to the data made available in this article, unless otherwise stated. 